\title{
DA AUTONOMIA MUNICIPAL EM FACE DAS ENTIDADES REGIONAIS
}

\author{
Edson Ricardo Saleme ${ }^{1}$ \\ Renata Soares Bonavides ${ }^{2}$
}

\section{Resumo:}

Este artigo objetiva estudar a posição federativa do Município e as possibilidades de governança metropolitana funcional como mecanismo eficaz para possível solução de questões ambientais diante da necessidade de soluções dos problemas decorrentes do fenômeno crescente da urbanização. Considerando a crescente relação de dependência entre as cidades na atualidade, inevitáveis problemas surgem desse intercâmbio. A partir de uma base conceitual subjacente de governança, que corresponde ao processo pelo qual uma determinada sociedade se dirige, é possível encontrar uma governança metropolitana efetiva e capaz de responder às demandas ambientais. Aqui se emprega o método hipotético-dedutivo e metodologia bibliográfica e documental.

Palavras-chave: autonomia municipal; entidade regional, estatuto da metrópole; entidade metropolitana; governança interfederativa

\section{MUNICIPAL AUTONOMY AND REGIONAL ENTITIES}

\begin{abstract}
:
This paper is to present the possibilities of functional metropolitan governance as an effective mechanism for the possible solution of environmental issues in view of the need to solve problems arising from the growing phenomenon of urbanization. Considering the relationship of dependency between cities today, inevitable problems arise from this exchange between cities. From an underlying conceptual basis of governance, which corresponds to the process by which a particular society is directed, it is possible to find effective metropolitan governance capable of responding to environmental demands. Here the hypotheticaldeductive method and bibliographic and documentary methodology are employed.
\end{abstract}

Keywords: Municipal autonomy; regional entities; governance; metropolitan Law; metropolitan entity

\section{Introdução.}

Os municípios são entes federativos peculiares da federação brasileira. O Federalismo de implantado pela Constituição Federal deste país reconhece no Município

\footnotetext{
${ }^{1}$ Pós-doutor em Direito pela UFSC. Doutor em Direito pela USP. Professor do Curso Stricto Sensu em Direito Ambiental Internacional da Universidade Católica de Santos. Consultor do IBAMA. E-mail ricasal@unisantos.br.

2 Doutora e Mestra em Direito. Diretora e Professora do Curso de Direito da Universidade Católica de Santos. Professora do Curso stricto sensu da Unisantos. Advogada em Santos. E-mail: renatasbonavides@gmail.com
} 
verdadeiro ente estatal, com todas as prerrogativas inerentes a qualquer ente federativo com personalidade jurídica de direito interno. $\mathrm{O}$ art. $1^{\mathrm{o}}$ da Constituição Federal autentica esse entendimento ao dispor quem são as unidades federativas brasileiras e o município não poderia deixar de ali estar. Na verdade, essa entidade estabeleceu-se como berço da sociedade, pois foi o gérmen dos demais entes.

O Brasil com suas dimensões continentais é o país da quinta maior extensão territorial do mundo. É certo que a centralização do poder não se coaduna com um território com dimensões continentais, sobretudo pelo fato da centralização não atender adequadamente aos problemas sociais que se consolidavam em localidades distantes. A federação estabelecida pelas Constituições brasileiras busca a materialização da consolidação da hierarquia constitucional. A relação entre as entidades federativas representa o compartilhamento de poder que também tem o benefício de descentralizar o poder para manutenção de uma democracia estabelecida e contenção de poder.

A onda de criação de municípios no Brasil teve também como objetivo a maior aproximação do Estado em face das populações em geral. O distanciamento geográfico e político deveria se tornar menor em favor de comunidades distantes para que todos pudessem ter acesso às políticas públicas oferecidas.

O país após as décadas de centralização política, no regime militar, diante da atuação decisiva de forças centrífugas regionais bem como as forças em favor da redemocratização do país trouxeram a nova realidade existente. É possível afirmar que a outorga de competências tributárias e transferências interfederativas permitiram aos municípios a autonomia financeira adequada para sua gestão. Esse processo de municipalização trouxe uma oportunidade institucional favorável ao poder municipal. Além disso, a descentralização política conferida ao ente garantiu às populações o acesso a políticas mais adequadas e fortaleceu o município na medida em que viabilizou a eleição dos cargos do Executivo e do Legislativo.

Mesmo diante desse reconhecimento do ente municipal tornando-o verdadeiro elemento da federação, o $\S 3^{\circ}$ do art. 25 da Constituição Federal, permitiu que os estados, por meio de lei complementar, criassem entidades interfederativas regionais. $\mathrm{O}$ apertado orçamento municipal, diante da realidade de grande parte dos municípios nacionais, não 
atendia a solução para problemas metropolitanos. Esta situação peculiar contou com um ente autárquico regional a busca solução dos problemas mais prementes.

Em face dessa realidade, que não foi introduzida pela Lei 13.089. de 2015, mas já existia desde 1973, ou seja, o crescimento urbano e o fenômeno de saída do meio rural para as cidades intensificou-se de tal forma que a solução encontrada foi a criação de entidades regionais com o intuito de desenvolver as funções públicas de interesse comum. O que se questiona neste trabalho é se o estabelecimento de tais entidades enfraquece a entidade municipal?

Esta questão é o que se pretende aqui buscar uma resposta. O que se tem ainda no Estatuto da Metrópole é a determinação dos planos diretores seguirem o que estabelece o Plano Diretor Urbano Integrado (PDUI), obrigatório para municipalidades que sejam obrigadas a criar seu respectivo plano.

O método aqui empregado é o hipotético-dedutivo e a metodologia é a bibliográfica e documental. Esta consultou doutrina especializada. A pesquisa também é oriunda de grupo de pesquisas de curso de pós-graduação e aqui se exporá alguns aspectos relevantes que atingem as entidades metropolitanas.

\section{1 - A autonomia municipal}

A preferência pela vida nas cidades tornou-se cada vez mais evidente na história do País. A partir da década de 1870, a tendência popular de manutenção em solo rural. A partir daí paulatinamente houve movimento migratório em direção aos centros urbanos. Neles parecia evidente a promessa de trabalho e melhores condições de vida.

A rápida urbanização e o célere crescimento demográfico nas cidades trouxeram a necessidade de institucionalização do planejamento urbano. Porém, isto ocorreu cem anos mais tarde, em 1970, com a missão de promover o desenvolvimento integrado; nas palavras de Raquel Rolnik (2001, 155-120) consolidou-se a chamada "clivagem da paisagem urbana, na qual existia um contraste considerável. Uma parte da cidade que teria condições de urbanização era dotada de infraestrutura completa. Outra parte, duas ou três vezes maior que a primeira, permanecia incompleta com urbanismo inexistente. 
Mesmo diante do desequilíbrio notório das cidades que se desenvolviam de maneira desigual em seu próprio território e apesar de certa precariedade em sua composição e formação, esse ente federativo no mundo moderno. Hely Lopes Meirelles (1985) chama a atenção ao fato de que o município no mundo hodierno diversificou-se em estrutura e atribuições. Possui normas próprias e assume grandes responsabilidades e incumbências administrativas no âmbito local. Nesse sentido, as atribuições edilícias da antiguidade meramente administrativas das urbes cederam espaço a funções político administrativas em âmbito municipal.

Na história brasileira se pode citar o Rio de Janeiro como uma das primeiras cidades a se desenvolver. Esta crescia sem qualquer planejamento, como qualquer outra, destaca Santana e Soares (2009). Grande parte da população residia em cortiços e cômodos sem qualquer infraestrutura capaz de proporcionar higiene. No inicio de sua formação buscou-se alguma forma de reorganização com a chama "Reforma Pereira Passos", conhecida localmente como "Bota-abaixo".

Tudo isto fez com que o Município passasse a se destacar como ente autônomo. Todos os movimentos foram em torno de torná-lo um ente próprio com políticas locais a fim de transformá-lo em um agente transformador da realidade local. $\mathrm{Na}$ verdade, atualmente, o desenvolvimento social depende de políticas urbanas integradas com o poder público federal e estadual.

Nesse diapasão a Constituição vigente estabeleceu que a matéria urbanística é de natureza concorrente, restrita à União, estados e Distrito Federal, nos termos do art. 21, XX.O município não faz parte dos entes contemplados neste dispositivo. Isso não impede que este ente possa suplementar a legislação federal e estadual no que couber, como preceitua o art. 30, II da CF.

A Carta Magna ainda confere à União o poder de legislar em termos de instituição de diretrizes para o desenvolvimento urbano, habitação, saneamento básico e transportes urbanos. Estes itens já são objeto de legislação própria: o Estatuto da Cidade trata de grande parte dos assuntos, Lei 10.257, de 2001. Há também as diretrizes da Política Nacional de Mobilidade Urbana, nos termos da Lei 12.587, de 2012, objetivando a integração entre os diferentes modos de transporte, bem como incrementando a mobilidade e acessibilidade de 
pessoas no território municipal. Destaca-se neste contexto ainda a competência da União para legislar a fim de "instituir diretrizes para o desenvolvimento urbano, habitação, saneamento básico e transportes urbanos", nos termos do art. 21, XX da CF. Este assunto também foi objeto de normas urbanísticas e sobretudo da Lei no 11.977, de 2009 e Lei no 13.465, de 2017.

Cabe aqui esclarecer que o fenômeno da urbanização, relacionado às cidades, como explica José Afonso da Silva (2012, p. 26) seria “o processo pelo qual a população urbana cresce em proporção superior à população rural. Não se trata de mero crescimento das cidades, mas de um fenômeno de concentração urbana."

Por outro lado, alerta o autor, a urbanização tem a característica de concentrar grande número de pessoas e ao mesmo tempo provoca a deterioração do ambiente local, a desorganização social, carência de habitação, problemas relacionados ao saneamento básico e outros de utilização do solo e transformadores da paisagem urbana.

Observa-se que a Constituição Federal estabeleceu competência concorrente a fim de ser elaborada norma geral para a regulação de institutos de direito urbanístico e de mobilidade urbana, o que já existe na atualidade. Também há norma acerca da regularização fundiária urbana, cumprindo outra determinação constitucional e o mais importante é a competência do art. 30, VIII da CF que estabelece a competência municipal de promover o adequado ordenamento territorial, mediante planejamento e controle do uso, do parcelamento e da ocupação do solo urbano. Aqui se identifica a entidade municipal como sendo aquela que possui maior proximidade com a população local e que pode identificar as áreas em que a municipalidade pode expandir seus limites e realizar as obras consideradas fundamentais.

\section{Problemas decorrente da gestão municipal}

A autonomia municipal e seu desenvolvimento geraram despesas de grande monta, o que não foi acompanhado pela distribuição de competências tributárias constitucionalmente estabelecidas. A Constituição não solucionou a questão da provisão de recursos financeiros suficientes para que se desempenhasse de maneira eficiente o grande número de serviços públicos a cargo do município. Assim, o elevado número de serviços públicos locais, a exemplo do saneamento básico, limpeza pública, entre outros relevantes para a localidade, são muitas vezes, quando são, desempenhados de forma precária por esses entes. 
O afluxo desordenado de pessoas para centros urbanos, nas palavras de Paulo Velten Pereira (759 - 799), gerou uma disputa natural pelo solo urbano. A população de baixa renda, geralmente ocupante de locais sem infraestrutura básica, passaram a ocupar a periferia em loteamentos precários aí situados, marcados pela irregularidade administrativa. O poder público municipal tem uma obrigação positiva: precisa administrar essa situação e não se manter omisso.

As competências municipais são basicamente, conforme Giambiagi e Além (2008): tributária, pela qual se arrecada e gerencia os recursos captados; competência financeira, a fim de zelar pelo equilíbrio e transparência da administração local; e administrativa, com o intuito de gerenciar humanos e patrimoniais. Ainda que existam dispositivos normativos capazes de conferir competência privativa municipal para instituir e em arrecadar tributos específicos, a geração de recursos próprios é muito baixa nessas entidades federativas. Basicamente sua fonte fundamental de recursos reside em seus tributos, que envolvem os taxas, contribuições de melhoria e os impostos que estão dispostos de maneira .

Para atender a necessidade de desempenho de serviços públicos e conciliar a estratégia política relacionada à autonomia municipal estabelecida constitucionalmente, a criação de consórcios intermunicipais parece ter viabilizado uma fórmula capaz de conciliar interesses e finalmente ofertar o serviço a população envolvida. Os consórcios públicos foram viabilizados por meio da Lei $\mathrm{n}^{\mathrm{o}} 11.107$, de 2005. Outra forma de cooperação, como bem atentou Prates (p.48-49, 2012) que se diferencia dessa formação consorcial é a por meio de práticas de gestão associada de serviços públicos. Esta forma, prevista no art. 241 da CF, é uma possibilidade que se disponibiliza às municipalidades os denominados "convênios de cooperação". Ao contrário dos consórcios públicos, estes entes não possuem um órgão a quem se transfere a execução dos serviços. De qualquer forma, o autor bem esclarece que deve existir um contrato de programa, previsto pela Lei dos Consórcios Públicos

\section{Entidades metropolitanas}

As discussões acerca das competências relacionadas a serviços públicos na Constituinte brasileira despenderam considerável tempo, pois sua prestação demandaria 
necessidade de recursos suficientes para custeá-los, seja por meio de tributos ou mesmo repasses de outros entes federativos.

Diante das normas já elaboradas há clara indicação de que o Município é ente federativo independente, sem qualquer submissão ao Estado ou à União, como bem ponderou Paulo Brum Ferreira (1995), isto porque, "nenhuma dessas entidades pode substituir o Governo local na solução de casos afetos à Administração Municipal. É o princípio da autonomia e a Constituição Federal. Além de inscrever a autonomia como prerrogativa do Município, incorporou alguns princípios asseguradores dessa autonomia [...]”

Assim, a autonomia municipal, seguindo ainda o autor, é assegurada pela eletividade dos prefeitos e vereadores; administração própria no que toca ao denominado "peculiar interesse"; criação, arrecadação de tributos e aplicação de rendas e organização de serviços públicos municipais. Estas seriam as peculiaridades que marcam a autonomia municipal e seu reconhecimento em face da Constituição brasileira.

Interessante o fato de ainda Brum Ferreira (1995) destacar que esse processo de descentralização redunda na necessidade de o governo necessitar investir considerável parcela de recursos "na qualificação técnica, no desenvolvimento profissional, principalmente de agentes públicos e da sociedade civil, hoje envolvidos nesse processo no âmbito dos Estados e Municípios.

Nas palavras de Petrônio Braz (2001, p. 93) “[...] o interesse ipso jure constitui-se no liame de ligação entre o Município e o exercício de sua finalidade existencial. Pelo preceito constitucional contido no art. 30,I, todos os atos que visem a realização dos objetivos do Município, que não conflitem com os interesses da União e/ou Estado-membro, podem ser por ele praticados."

Este talvez seja o ponto mais crítico relacionado à prestação de serviços públicos em sede municipal. Não há servidores especializados para o assessoramento em determinados tipos de atos que o ente é obrigado a estabelecer, assim como não há receita suficiente para a contratação de terceiros para a prestação de serviço técnico. BREMAEKER (1996) remarca acertadamente que as municipalidades de “[...] economia tipicamente rural não possuem uma 
massa de contribuintes que lhe possibilite ter uma receita tributária expressiva. Além do mais, os tributos que cabem ao Município cobrar são quase todos de natureza tipicamente urbana"

Cabe ainda ressaltar que os municípios criados há pouco tempo sequer possuem condições para assumir as despesas com os titulares dos cargos do Executivo e Legislativo. Não há recursos suficientes para tais gastos, o que se poderia ainda cogitar em outras despesas mais onerosas que ficarão a cargo do ente recém-emancipado. Existe a Proposta de Emenda à Constituição n. 188, de 2019 (Brasil, 2019), que propõe a incorporação de municípios deficitários por outros. Uma das justificativas oferecidas pelos autores é de que:

Temos mais de 5.500 Municípios no Brasil, sendo que, destes, mais de 1.200 possui população inferior a 5.000 habitantes e, em sua maioria, não arrecada receitas próprias suficientes para custear a sua própria estrutura (Prefeitura, Câmara de Vereadores etc.), isto é, custos que não existiriam (ou seriam substancialmente reduzidos) caso o Município fosse incorporado a outro.

É possível que a proposta jamais seja votada diante da pressão de municipalidades inconformadas, prefeitos, vereadores e servidores que perderiam sua posição. Porém, trata-se de uma fórmula que pode gerar receita para municípios que mal conseguem arcar com suas despesas regulares.

A concentração de população e de funções urbanas em determinadas capitais brasileiras levou o governo federal a reconhecer unilateralmente o processo de metropolização no Brasil, nas palavras de Pirajá Silva (2017). Este momento marcou a administração complexa da urbanização de municipalidades que concentravam grande massa populacional, atividades e riquezas, criando espaços urbanizados multifuncionais e bastante integrados à economia nacional e internacional.

A autora segue em sua explanação afirmando que a população urbana brasileira “[...] passou de aproximadamente 19 milhões, em 1950, para quase 161 milhões de habitantes, em 2010. Entre as décadas de 50-60 e 60-70, a população urbana do Brasil cresceu mais de 5\% a.a. [...]. Em 2010, 14 municípios possuem mais de um milhão de habitantes vivendo em áreas urbanas.

As entidades metropolitanas já existiam. Entretanto, necessitavam de estrutura capaz de albergar necessidades relacionadas a diversas municipalidades, geralmente conturbadas. $\mathrm{O}$ 
conceito de Almeida (2001) é o mais seguro a ser considerado por mantém as unidades federativas em sua integralidade e autonomia. Nesse sentido, para ele a entidade metropolitana é uma organização política com base territorial definida estabelecida com bases de poder e autoridade entre instâncias de governo, constitucionalmente definida e assegurada. Desta forma o governo estadual e os municipais são independentes nas suas esferas próprias de ação.

Esta iniciativa estabeleceu a necessidade de criação de um texto para melhor implementar as entidades regionais. Diversos especialistas debateram projetos com convidados de diversas entidades de regiões metropolitanas (RMs), conforme esclarece Marcela de Oliveira Santos (2018; p. 461 - 515). Diversas contribuições foram consideradas chegando-se a redação atual, que já recebeu emenda. A autora recorda que no tempo da tramitação do Estatuto da Cidade, Lei n ${ }^{\circ}$ 10.257, de 10 de julho de 2001, buscou-se inserir capítulo sobre as entidades regionais. A ideia não prosperou, pois interpretou-se que caberia apenas aos estados federados legislar a respeito da matéria, em leitura do art. 25, § 3o , da CF, tratando a questão como competência estadual exclusiva.

Porém, reabriu-se a necessidade de se implementar uma norma em nível nacional, o que ocorreu por meio da Lei 13.089, de 2015. Esta Lei regulamentou as regiões metropolitanas, aglomerações urbanas e microrregiões com características urbanas, todos são considerados entidades regionais. O objetivo da norma foi a institucionalizações delas e a realização (organização, planejamento e execução) das funções públicas de interesse comum (FPICs).

A institucionalização de uma entidade regional é essencialmente de caráter político, (estabelecida por um ou mais estados-membros) que a institui com finalidades diversas: execução das funções públicas de interesse comum instituídas pelos estados; criação do plano de desenvolvimento urbano integrado (PDUI); normas gerais para a elaboração dos instrumentos de governança interfederativa e apoio à União em ações que objetivem viabilizar o desenvolvimento urbano.

O IPEA - Instiuto de Pesquisa Econômica Aplicada, vinculado ao Ministério do Planejamento, Desenvolvimento e Gestão (2019), propôs-se, por meio do site "governança 
metropolitana", a viabilizar o que pode auxiliar ou não a governança interfederativa. O projeto está em permanente fase de levantamento e observação de peculiaridades na gestão metropolitana nas principais regiões metropolitanas brasileiras. Nesse sentido, há uma mobilização considerável em prol da concretização dos objetivos do Estatuto da Metrópole e outras normas urbanísticas que buscam consolidar conceitos e reestruturação produtiva das atividades econômicas nessas entidades.

Por outro ângulo Marcela de Oliveira Santos (2018; p. 59-111), em outro estudo afirma que a autonomia do município e sua ascensão à categoria de ente federativo estabeleceu uma “[...] tentativa de municipalização das políticas e dos recursos públicos, enfraquecendo os mecanismos de planejamento e execução de atividades em nível regional."

Entretanto, essa tentativa não foi bem sucedida. O aumento das funções do Estado, da complexidade sociopolítica determinou de maneira absoluta o retorno da intervenção estatal e a reformulação das políticas públicas estruturadas em diversas dimensões: organização, planejamento, execução e controle.

Contribuiu igualmente para esse fenômeno a falta de arrecadação local, o que outra solução não houve senão o município ter que contar com um ente estatal que pudesse desempenhar serviços onerosos e em uma base territorial que escapava de sua simples circunscrição.

\section{Dificuldades na implementação da entidade metropolitana e questões municipais}

Diante da necessidade de criação de um ente regional para conduzir os serviços públicos enquadráveis na categoria de função pública de interesse comum FPIC deveriam ser custeados por um fundo. Este talvez seja o elemento mais crucial da entidade: a arrecadação de fundos para organização dos serviços e sua respectiva prestação.

Este elemento, na visão de Marcela Santos (2018; p. 84), é um dos principais gargalos da gestão metropolitana, pois há dificuldades em se estabelecer um sistema de alocação de recursos que viabilize não somente o custeio, mas também a organização e planejamento das 
referidas funções em âmbito metropolitano. Este é o denominado financiamento metropolitano, crucial para operações exitosas em termos de operações coordenadas pela agência regional.

Sob o escólio da autora, a Lei $\mathrm{n}^{\mathrm{o}} 13.089$, de 2015, não foi suficientemente clara ao tratar do assunto, pois apenas indicou a necessidade em se estabelecer na estrutura de governança metropolitana um "sistema integrado de alocação de recursos" e também esclareceu que seriam indispensáveis "fundos públicos", a fim de se obter bons resultados em termos de desenvolvimento urbano integrado.

No tocante ao elemento financeiro, que pode oferecer suporte a essas entidades, nos termos esclarecidos por Marco Aurélio Costa (2018; p. 140-177), de que as capacidades que compõe uma região metropolitana é bastante heterogêneo. São desiguais. O Município pólo apresenta indicadores fiscais mais promissores. Possui níveis de arrecadação tributária mais elevados. Entretanto, não se pode comprometer a estrutura orçamentária desse ente para o financiamento da estrutura metropolitana.

Para a contribuição deste fundo é fundamental que os entes federativos participantes da região metropolitana possam se auto-reconhecer como tais. Razão assiste a Alaôr Caffé Alves (2011, p. 66) que bem esclarece o fato de que o município tradicional engole a cidade, mas o município metropolitano, ao revés, é engolido pela grande cidade. Nesse sentido, o vínculo regional não pode ser criado pelo Estado de maneira arbitrária, ou seja, não poderia ele indicar quais seriam os municípios que deveria englobar ou não determinada região, pois isso deveria ocorrer por meio de uma realidade urbana conurbada e comprovada, seja por meio de uma análise local ou mesmo por pareceres técnicos.

A realidade comprova um certo desentendimento entre a realidade e os diversos institutos estudados em face das entidades regionais. Observou-se que, por ocasião dos eventos internacionais sediados pelo Brasil, diversas regiões metropolitanas foram criadas e ainda continuam ativas, mesmo inocorrendo o fenômeno da conurbação que, segundo juristas e mesmo o Estatuto da Metrópole, seria condição essencial à formação delas.

O governo federal, desde os anos 60, já observava que grande parte dos municípios, que apresentava essa população significativa, tinha dificuldades em prestar determinados tipos 
de serviços, sobretudo os envolvidos em regiões metropolitanas situadas nas capitais dos estados, devido ao grande fluxo migratório. Nesse sentido, se constatava ausência de moradia, prestação inadequada de serviços públicos essenciais e também a questão viária que passou a ser uma das mais debatidas em

Contudo, o que se discute nesta parte final é a questão financeira. Esta sim é a mais complexa no arranjo metropolitano, pois os municípios estão com orçamentos cada vez menores, o que lhes impulsiona a ser parte dessas entidades. Grande parte das vezes os municípios estão dispostos a ingressar nessa associação, sobretudo por lhe garantir a disponibilização de serviços que, sem a autarquia estadual, não lograria oferecer.

Inicialmente cabe esclarecer os estudos de Mariana Mencio (2013) em que, a princípio, a partir da Constituição vigente, o reconhecimento e municípios como entes federados trouxe ainda maior complexidade para a legitimação dos estados como órgão de coordenação. Porém, diversas experiências metropolitanas contribuíram para fortalecer vínculos compulsórios entre municípios.

A autora segue em sua exposição afirmando que a criação dessas entidades acolheu o modelo de gestão compartilhada entre estados e municípios das funções públicas de interesse comum. A autarquia estadual correspondente deveria conduzir os trabalhos a partir de órgãos deliberativos e consultivos que garantam a participação paritária dos entes envolvidos por meio e arranjo institucional. De forma a proteger a autonomia Municipal destaca-se que grande parte dos arranjos regionais contemplam a todos os entes participantes formas paritárias de manifestação e opinião.

Relativamente aos aportes financeiros necessários ao desempenho das funções públicas de interesse comum que a entidade regional deve desempenhar pode-se oferecer como exemplo o Fundo de Desenvolvimento Metropolitano da Baixada Santista (FUNDO). Regulamentado por meio do Decreto 42.833, de 1998, do Estado de São Paulo, a Região Metropolitana da Baixada Santista estabeleceu essa formula como meio de financiar o planejamento integrado e as ações conjuntas dele decorrente, no que se refere às funções de interesse comum entre Estado e municípios integrantes. 
As entidades regionais têm sérios problemas a serem enfrentados, mesmo contando com a Lei 13.089, de 2015. Como esclarece CARRIÇO e VIANA (2018, p. 17), existem percalços em questões de legitimidade política e institucional, pois o território das entidades regionais não se transformou em território político. Seguem sendo unidades administrativas. Isto ocorre em face da ausência de quadro institucional capaz de construir de forma adequada a governança nesses territórios. Por este motivo seguirão tendo obstáculos de diversas ordens em decorrência de sua própria estrutura peculiar.

Os autores esclarecem que o Brasil contava em 2012 com 59 unidades regionais urbanas institucionalizadas como regiões metropolitanas, regiões integradas de desenvolvimento e aglomerados urbanos. Em 2015 esse número saltou para 78 unidades regionais, sendo que ainda existem grupamentos a serem aprovados até a presente data. A constatação que merece destaque é que toda entidade deve ser tratada de maneira individualizada como grupamento que é, com suas próprias peculiaridades.

\section{Considerações finais}

Os municípios passaram a concentrar grande número de pessoas oriundas do meio rural faz considerável tempo. O que se notou é que as cidades contempladas com esse contingente populacional cresceram de forma desigual. Um terço recebia alguma infraestrutura dotada de equipamentos urbanísticos e a outra parte, maior, mantinha-se estagnada com pequenos núcleos populacionais. Porém, o que mais se observou foi a degradação ambiental nociva sofrida por esse contingente populacional sem precedentes.

O crescimento das cidades gerou degradação considerável e isso era observado como fenômeno sem relevância, assim como o elevado contingente populacional passava a consumir a cidade que habitava além de outras que eram "tragadas" diante desse aumento desordenado.

Diante do efeito da conurbação de diversos centros urbanos, a União decidiu criar as regiões metropolitana, sempre com vistas ao desempenho dos denominadas funções públicas de interesse comum para que fossem prestadas por ela serviços relevantes diante do orçamento limitado insuficiente. Com a Constituição Federal vigente os estados passaram a ser os responsáveis pela criação das regiões metropolitanas, por meio de lei complementar, 
agomerações urbanas e microrregiões, com o intuito de ordenar e desenvolver a circunscrição regional afetada por grande massa poopulacional, nos termos do art. $25 \S 3^{\circ}$.

O Estatuto da Cidade, Lei $n^{\circ} 10.257$, de 2001, deveria fazer alguma regulamentação das entidades regonais. Porém, isso não ocorreu. Apenas com o advento do Estatuto da Metrópole, Lei 13.089, de 2015, é que se propôs a criação de uma governança interfederativa, o relevante desempenho de funções públicas de interesse comum pela entidade regional, o plano diretor urbano integrado (PDUI), que deve servir de paradigma para os planos diretores das municipalidades partícipes da entidade regional e outras figuras antes inexistentes ou pouco mencionadas como fundamentais.

As entidades regionais passaram a ocupar seu lugar adequado. A regulamentação do Estatuto da Metrópole já viabiliza dispositivos capazes de melhor conduzir essas regiões e seu desenvolvimento. Porém, aqui se questiona se essas entidades efetivamente geraram algum tipo de impacto na autonomia municipal, bem como em termos de competências a esse ente atribuída. Mesmo considerando benéfica a existência de uma norma como o Estatuto da Metrópole, o caminho a seguir ainda é desconhecido e as entidades regionais buscam soluções para problemas de envergadura, sobretudo de índole financeira.

O agrupamento de entidades regionais é significativo no território nacional. Eles são sinônimo de renovação e união em termos de prestação adequada de serviços comuns. O que se deve observar é que não há como se estabelecer procedimentos uniformes em cada uma das entidades, pois cada qual apresenta peculiaridades próprias.

A criação acelerada de municípios nas décadas passadas gerou efetivo impacto para as regiões que se situam. Na verdade, a situação é complexa. A PEC pode não ser a solução, mas é uma tentativa de viabilizar o uso de recursos captados por meio de tributos para o usufruto da população e não simplesmente para o pagamento de valores atinentes a agentes políticos e servidores das municipalidades, que sequer trabalham diariamente, em grande parte das municipalidades, diante da falta de recursos orçamentários.

Destarte, afirma-se que o Município, como ente federativo, perde parcela de sua competência federativa em prol da criação de entidade regional com finalidade de atender 
necessidades múltiplas atinentes a uma região metropolitana considerada em determinada lei complementar estadual. A teoria indica que devem existir estudos prévios para a criação dessas entidades e devem estar necessariamente conurbadas. A realidade comprova que isso não é uma realidade nacional, já que existem regiões metropolitanas na Região Norte brasileira que contempla município que dista há mais de cem quilômetros do centro metropolitano.

O Estatuto da Metrópole, Lei 13.089, de 2015, buscou contemplar determinadas regras em prol da formação e do crescimento ordenado das entidades regionais. Estabeleceu parâmetros para a governança interfederativa, indicou a necessidade de criação de um plano diretor urbano integrado e criou regras que, na maioria das vezes, não estão sendo observadas por motivos múltiplos.

\section{Referências}

AFONSO DA SILVA, José. Direito urbanístico brasileiro. São Paulo: Ed. Malheiros, 2014.

ALMEIDA, Maria Hermínia Tavares de. Federalismo, Democracia e Governo no Brasii: Ideias, Hipóteses e Evidências. Bib: Revista Brasileira de Informação Bibliográfica em Ciências Sociais, São Paulo, n. 51, p.13-34, 2001.

ALVES, Alaôr Caffé. Regiões Metropolitanas, aglomerações urbanas e microrregiões. Novas dimensões constitucionais do Estado brasileiro. Revista de Direito Ambiental 21, ano 6 jan-mar. São Paulo: RT, 2011.

BRAS, Petrônio. Direito municipal na Constituiçãa. Leme: Editora de Direito (LED), 2001.

BRASIL, Senado Federal. Proposta de Emenda à Constituição n. 188 de 2019. Disponível em https://legis.senado.leg.br/sdleggetter/documento?dm=8035580\&ts=1576105226199\&disposition=inline. Acesso em 2.10.2019.

BREMAEKER, F.E.J. "Limites à criação de novos municípios:? A emenda constitucional no 15". Rio de Janeiro: Revista de Administração Municiap, 43 (219(: 118-128, abril/dezembro.

CARRIÇO, José Marques e VIANA, Mônica. Aspectos introdutórios ao Estatuto da Metrópole. In Comentários ao Estatuto da Metrópole. Org. Carriço, José Marques e SALEME, Edson R. Santos: Leopoldianum, 2018.

COSTA, Marco Aurélio. Financiamento metropolitano no Brasil: um panorama de suas condições, seus desafios e suas perspectivas. Brasil metropolitana em foco. Desafios à implementação do Estatuto da Metrópole. Marguti, Barbara Oliveira, COSTA, Marco Aurélio e FAVARÃO, Cesar Bruno (orgs). Disponível em 
http://www.ipea.gov.br/portal/images/stories/PDFs/livros/livros/180410_brasil_metropolitano _em_foco.pdf. Acesso em 3.10.2019.

FERREIRA, Paulo Brum. O modelo federativo brasileiro: evolução, o marco da Constituição de 1988 e perspectivas.In Subsidiariedade e fortalecimento do poder local

GIAMBIAGI, Fabio; ALÉM, Ana Claudia. Finanças públicas: teoria e prática no Brasil. Rio de Janeiro: Campus, 2008.

LAMAS, José Manuel Ressano Garcia Lamas. Morfologia Urbana e Desenho da Cidade. Porto: Fundação Calouste Gulbenkian, 2004.

LEFEBVRE, Henri. A revolução urbana. Tradução de Sérgio Martins. Belo Horizonte: Ed. UFMG, 1999. O direito à cidade. Tradução de Rubens Eduardo Frias. São Paulo: Centauro, 1969.

MARICATO, Ermínia. Brasil, cidades: alternativas para a crise urbana. $3^{\mathrm{a}}$ ed. Petrópolis, RJ: Vozes, 2008.

MINISTÉRIO DO PLANEJAMENTO, DESENVOLVIMENTO E GESTÃO. Governança metropolitana. IPEA. Disponível em http://brasilmetropolitano.ipea.gov.br/\#projeto, acesso em 3.10.2019. 1985.

MEIRELLES, Hely Lopes. Direito municipal brasileiro. São Paulo: Malheiros,

MENCIO, Mariana. Oregime jurídico do plano diretor das regiões metropolitanas. Tese apresentada à Banca examinadora da PUC-SP para obtenção do título de doutorado sob orientação do Prof. Dr. Marcio Cammarosano.

PRATES, Angelo Marcos Queiroz. Federalismo no Brasil: os consórcios públicos intermunicipais no período recente. Tese de doutorado apresentada ao Programa de pósgraduação em Desenvolvimento Econômico, orientada por Cláudio Schuller Macial. Campinas, 2012.

ROLNIK, Raquel. Planejamento e gestão: um diálogo de surdos. In Estatuto da Cidade. Coord. MOREIRA, Mariana. São Paulo: CEPAM, 2001.

SALEME, Edson Ricardo; e CARRIÇO, José Marques (Organizadores). Comentários ao Estatuto da Metrópole.Santos. Editora Universitária Leopoldianum, 2018.

SANTANA, Fabio Tadeu de Macedo e SOARES, Marcus Rosa. Reforma Passos: cem anos de uma intervenção excludente. 2009.

SANTOS, Marcela de Oliveira. Interpretando o Estatuto da Metrópole: comentários. In Brasil metropolitano em foco : desafios à implementação do Estatuto da Metrópole / organizadores: MARGUTI, Bárbara Oliveira e FAVARÃO, César Buno e COSTA, Marco Aurélio. Brasília: Ipea, 2018. Série Rede Ipea. Projeto Governança Metropolitana no Brasil; v. 4. 
SILVA, Maina Piraja.O papel dirigente nas regiões metropolitanas de Salvador, Recife e Fortaleza: dinâmicas e limitações.Tese de Doutorado apresentada ao Programa de Pós-Graduação em Geografia, da Universidade Federal da Bahia, como requisito para obtenção do título de Doutora em Geografia, 2017.

URANI, A. O papel do setor privado e da sociedade civil nas novas governanças metropolitanas brasileiras. In: MAGALHÃES, F. (Ed.). Regiões metropolitanas no Brasil: um paradoxo de desafios e oportunidades. New York/Washington: BID, 2010. p. 123-168. 